\title{
Um currículo para a expressão e a apropriação da subjetividade: análise de práticas de ampliação da escolaridade dos trabalhadores nas empresas
}

\author{
Moacir Fernando Viegas \\ Universidade de Santa Cruz do Sul (Unisc)
}

\begin{abstract}
O objetivo do presente trabalho é analisar as implicações do currículo dos cursos de ampliação da escolaridade dos trabalhadores que as empresas têm implementado enquanto unidades particulares de produção ou em associação com o poder público, as universidades e outras empresas, no que diz respeito à formação do trabalhador "flexível". Tais cursos visam adequar a formação dos trabalhadores às necessidades das novas tecnologias de produção, rompendo com a educação taylorista recebida nos poucos anos de escolarização desses trabalhadores. A base empírica para nossa discussão é uma pesquisa na qual investigamos as práticas pedagógicas de ampliação da escolaridade realizadas por dez empresas das regiões do Vale do Rio Pardo e da grande Porto Alegre, no Rio Grande do Sul. O estudo revela que o currículo dessas práticas, especialmente o currículo em ação ao qual aqui damos destaque, funciona como instrumento de apropriação das capacidades subjetivas dos trabalhadores. Procuramos demonstrar também que essas práticas pedagógicas contribuem para o deslocamento do trabalho prescrito para o terreno da missão da empresa.
\end{abstract}

Palavras-chave: Educação e trabalho, Educação de jovens e adultos, Subjetividade, Qualificação.

A curriculum for the expression and appropriation of subjectivity: an analysis of the practices for schooling improvement among factory workers

This paper aims to analyze the implications of curricula of courses for schooling improvement of workers which have been developed by companies while specific production units or in association with the government, universities and other companies, regarding the formation of "flexible" workers. Such courses seek to align the workers' formation with the need for new technologies of production, breaking with the taylorist-rooted education received by those workers in their few schooling years. As an empirical basis for our research is a survey where we have investigated the pedagogical practices for schooling improvement carried out by ten companies in the Vale do Rio Pardo and Greater Porto Alegre, Rio Grande do Sul, Brazil. The study reveals that these practices' curricula, especially the one herein focused, work as a tool for the appropriation of the workers' subjective capacities. We have also sought to demonstrate that these pedagogical practices contribute for the dislocation of the prescribed work into the realm of the company's mission.

Keywords: Education and work, Youth and adult education, Subjectivity, Qualification.

T ornou-se consenso no meio acadêmico educacional, já há algum tempo, que as mudanças na produção econômica ocorridas a partir da década de 70 resultaram em alterações significativas dos conhecimentos valorizados no trabalho e nas práticas educativas na escola. No que diz respeito à educação de jovens e adultos, é interessante notar como as empresas tomaram a dianteira das mudanças, ao instituir, ao longo da década de 90, uma série de iniciativas visando um aumento da escolarização de seus funcionários que atendesse às necessidades das novas tecnologias de informação e à globalização econômica ${ }^{1}$. A reforma educacional na educação de jovens que adultos - que tenta ainda superar as concepções do velho ensino supletivo, estando longe de consegui-lo, sem dúvida -, tem início apenas em 2000, com a regulamentação das novas Diretrizes Curriculares.

1 São exemplos desse pioneirismo as já clássicas experiências de educação de jovens e adultos desenvolvidas pela Azaléia, no Rio Grande do Sul, e pela Ford, em São Paulo, nos anos 80 e 90. 
As empresas não podiam esperar, pois o processo de globalização andava já a passos largos na década de 90 e era necessário adaptar-se urgentemente aos novos padrões de produção internacionais, sob pena de perda de competitividade. E, de fato, as empresas que tomaram a dianteira obtiveram muitas vantagens, como se pode ver pela afirmação da diretora de uma indústria produtora de alimentos: "quando a globalização começou a se acirrar, a gente fez um trabalho muito grande dentro da escola. Os alunos eram portadores das informações dentro da fábrica... formadores de opinião".

Assim, em certo sentido, as empresas foram pioneiras na instituição de um currículo de educação de jovens e adultos no que diz respeito às necessidades da globalização. Obviamente que fizeram isso segundo seus interesses e atendendo às exigências de reprodução de sua força de trabalho e não por uma questão de "cidadania", como afirma o diretor de uma indústria extrativista:

é verdade isso, espero que as pessoas cresçam como pessoas, um ambiente melhor, todo mundo amigo... mas a gente quer também que esse conhecimento possa ser aplicado em benefício dos setores de produção, que a gente possa ter um ganho em relação a isso... fazer efetivamente um melhor produto, com qualidade melhor, com um menor preço.

Consideramos o currículo como propriedade que caracteriza essencialmente a prática pedagógica, a partir da qual, portanto, podemos traçar suas características mais importantes. Amparados em pesquisa que realizamos sobre as práticas pedagógicas de ampliação da escolaridade desenvolvidas pelas empresas, analisaremos as implicações do currículo dessas práticas, especialmente do currículo em ação, no que diz respeito à formação trabalhador "flexível". Com base nas informações levantadas, pretendemos demonstrar, em primeiro lugar, que o currículo dessas práticas pedagógicas possibilita a apropriação das capacidades subjetivas dos trabalhadores. E, em segundo, que tais práticas expressam um deslocamento do caráter prescritivo do currículo fundado em bases tayloristas, para conteúdos mais subjetivos, ligados ao compromisso com a empresa.

Dividimos nossa análise em duas dimensões do currículo, que, para efeito de exposição, organizamos da seguinte maneira: a) aspectos formais prescritivos, como a organização curricular e os objetivos das propostas pedagógicas; b) o currículo em ação: forma de apropriação dos saberes dos trabalhadores; e c) o currículo em ação: deslocamento do currículo prescrito para o âmbito da produção do compromisso com a empresa.

É fundamental destacarmos que os saberes disseminados nos cursos que ampliam a escolaridade dos trabalhadores fazem parte de um terreno de conflito, de negociações e de lutas. Toda e qualquer situação de trabalho é o "lugar de um problema, de uma tensão problemática, de um espaço de possíveis sempre a negociar" (Schwartz, 1992, citado por Rosa, 1998, p. 134). Não convém, mesmo ao taylorismo, que seja totalmente dispensada a possibilidade de realização de escolhas pelos trabalhadores, as quais em certa medida fogem ao controle do trabalho prescrito. Para Schwartz (2002), a padronização perfeita é algo irrealizável e, nas "brechas de normas" presentes nas relações de trabalho, "os protagonistas devem construir para si mesmos normas para supri-las, para agir e administrar a situação (...) Com isso, essas reações saudáveis, tornadas necessárias pela impossibilidade de padronização, não cessam de produzir história (...)” (p. 118).

A impossibilidade de uma análise determinista do fenômeno em questão deve-se a que a base para nossa discussão sejam as relações sociais entre seres humanos no modo de produção capitalista, que opõe classes sociais com interesses distintos. Como afirma Wood (2003), "a esfera econômica tem em si uma dimensão jurídica e política. Num certo sentido, a diferenciação da esfera econômica propriamente dita quer dizer apenas que a economia tem suas próprias formas jurídicas e políticas, cujo propósito é 'puramente' econômico” (p. 35). 


\section{Aspectos metodológicos}

$\mathrm{Na}$ pesquisa que serviu de base principal para o presente artigo, investigamos seis projetos de formação dos trabalhadores. Eles envolviam dez empresas do setor industrial, que atuam nos seguintes ramos de produção: alimentos, metalúrgico, extrativista, artigos de borracha, confecções, móveis, higiene e limpeza. A grande maioria dos projetos são realizados em parceria com universidades, secretarias municipais de educação, Serviço Social da Indústria (SESI) e Serviço Nacional de Aprendizagem Industrial (SENAI). Apenas uma das empresas investigadas possuía escola própria. Porém, em cinco delas as aulas ocorrem ou ocorreram, por um determinado período, no próprio lugar de trabalho. Em sete das empresas os alunos-trabalhadores recebem certificação na conclusão dos estudos. Nas demais, eles precisam realizar os exames supletivos oferecidos pelo Estado. Duas das empresas estão inseridas em projetos que compreendem o ensino fundamental completo e o médio. Seis, em práticas que envolvem apenas o ensino fundamental de quinta a oitava séries e duas na quais o nível oferecido é apenas o ensino médio.

Em função dessa diversidade, optamos por nomear as ações investigadas genericamente de práticas pedagógicas de ampliação da escolaridade, na medida em que essa denominação reflete seu objetivo principal que é ampliar a escolarização dos trabalhadores para adaptar a sua formação ao novo paradigma produtivo. Evidentemente existem especificidades nas experiências investigadas. Nosso objetivo aqui, no entanto, é destacar uma tendência geral que se apresenta nessas práticas, que é o fato de proporcionarem um melhor aproveitamento, para a produção econômica, das capacidades subjetivas dos trabalhadores, condição necessária ao desenvolvimento do novo paradigma produtivo.

Os grupos sociais que fizeram parte da pesquisa foram os gestores empresariais e educacionais, funcionários de recursos humanos das empresas, supervisores dos setores em que trabalham os operários que freqüentavam os cursos, professores, alunos e supervisores das instituições escolares envolvidas. O principal critério de escolha desses indivíduos foi seu grau de envolvimento com os trabalhadores que participam dos cursos.

Os dados totalizaram entrevistas com 19 alunos-trabalhadores, 10 funcionários de recursos humanos, 14 professores e professoras, oito supervisores de produção das empresas, quatro supervisores ligados às secretarias de educação, duas secretárias da educação, 14 funcionários (entre coordenadores regionais, locais e técnicos) da área de educação do SESI e do SENAI, seis gestores das empresas (diretores) e duas coordenadoras ligadas a uma universidade. Foram aplicados 120 questionários com os alunos-trabalhadores, que serviram de base para a escolha dos entrevistados. Também foram feitas nove observações semidirigidas das aulas, visitas à área de produção das empresas e análise dos projetos pedagógicos.

Conforme quadro abaixo, podemos ver que entre os trabalhadores que fizeram parte da pesquisa, a maioria possui entre a quarta e a sétima séries do ensino fundamental, o que mostra que a força de trabalho que está passando pelo processo de formação é aquela para a qual foram exigidos quatro ou pouco mais anos de estudo para ocupar os cargos em que estão.

Últimas séries concluídas pelos trabalhadores

\begin{tabular}{|c|c|c|c|c|c|c|c|c|}
\hline $2^{\underline{a}}$ & $3^{\underline{a}}$ & $4^{\underline{a}}$ & $5^{\underline{a}}$ & $6^{\underline{a}}$ & $7^{\underline{a}}$ & $8^{\underline{a}}$ & $1^{\underline{a}}$ & Não responderam \\
\hline 2 & 2 & 15 & 38 & 42 & 6 & 10 & 3 & 2 \\
\hline
\end{tabular}

A quase totalidade dos trabalhadores que realizam os cursos ocupa funções bastante desqualificadas. O grupo mais numeroso é o de operadores (35), depois os auxiliares de produção (15) e em terceiro lugar os que trabalham em serviços gerais (oito). Um grupo bem 
menor ocupa funções um pouco mais qualificadas, como torneiro, ferramenteiro ou almoxarife e apenas três ocupam cargos de chefia, como dois supervisores de produção e um encarregado.

Cargos ocupado pelos trabalhadores

\begin{tabular}{|l|c|l|c|}
\hline Operador & 35 & Chanfradeira & 1 \\
\hline Auxiliar de produção & 15 & Servente de pedreiro & 1 \\
\hline Serviços gerais & 8 & Controlador de atelier & 1 \\
\hline Ajudante & 5 & Auxiliar de almoxarifado & 1 \\
\hline Atendente de creche & 5 & Vendedora & 1 \\
\hline Manutenção mecânica & 4 & Camareira & 1 \\
\hline Pintor & 3 & Conferente & 1 \\
\hline Motorista & 3 & Líder de produção & 1 \\
\hline Autônomo & 3 & Almoxarife & 1 \\
\hline Marceneiro & 2 & Ferramenteiro & 1 \\
\hline Supervisor & 2 & Caldeireiro & 1 \\
\hline Balconista & 2 & Atomizador & 1 \\
\hline Montador & 2 & Prensista & 1 \\
\hline Soldador & 2 & Fresador & 1 \\
\hline Torneiro mecânico & 2 & Mandrilador & 1 \\
\hline Expedidor & 2 & Serralheiro & 1 \\
\hline Ajudante & 1 & Auxiliar de expedição & 1 \\
\hline Tratamento de sups. metálicas & 1 & Vigilante & 1 \\
\hline Separador & 1 & Não respondeu & \\
\hline Encarregado de expedição & & & 1 \\
\hline Pesador de produtos químicos & & 120 \\
\cline { 1 - 4 } & 1 & 1 \\
\hline
\end{tabular}

\section{Currículo, taylorismo-fordismo e economia baseada na informação}

O currículo é, no nosso entender, o aspecto essencial da escola. Compreendido aqui não apenas na sua formalidade, mas sim em todos os aspectos envolvidos na prática pedagógica, o currículo é o instrumento por excelência da formação escolar dos trabalhadores. Seguindo Sacristán e Gómez (1998), entendemos currículo como uma complexa articulação de elementos que se configuram na prática pedagógica. Desse modo, o currículo prescrito representa apenas um aspecto muito limitado do currículo, sendo seu efeito na formação dos estudantes mediado por um sem-número de elementos. Entre esses elementos estão, de um lado, o que os autores chamam de "atividades curriculares": a ordenação do próprio currículo (em séries, ciclos etc.), os textos escolares, os planos da escola, do professor, a avaliação e a inovação curricular. De outro lado, estão os "âmbitos" que modelam o currículo: o contexto exterior (influências sociais, econômicas, culturais etc.), as regulações políticas e administrativas, a produção de meios didáticos, a participação da família. O currículo sofre influência ainda da estrutura do sistema educativo, da organização e do ambiente da escola, do ambiente da sala de aula e das atividades de ensino-aprendizagem. 
Desse modo, Sacristán e Gómez entendem o currículo como um processo que envolve aspectos prescritos, de planejamento, avaliação, organizativos e, principalmente, o currículo em ação, ou seja, as aprendizagens e os conhecimentos presentes no cotidiano da prática pedagógica, na qual interagem os vários elementos da formação do aluno. No caso dos cursos de educação de jovens e adultos implementados pelas empresas, o currículo sofre influência direta das mudanças na produção, as quais, como afirma Kuenzer (1998), colocam em questão a construção de "uma nova proposta pedagógica de educação para os trabalhadores, que articula as capacidades de agir intelectualmente e pensar produtivamente" (p. 73).

Até o início dos anos 90, no Brasil, predominava uma concepção de organização curricular que correspondia às necessidades da produção em massa, objetivo do paradigma taylorista-fordista de produção, cujos princípios básicos foram elaborados por Bobbitt, para quem, segundo Silva (1999), o currículo "é um processo de racionalização de resultados educacionais, cuidadosa e rigorosamente especificados e medidos" (p. 12). A fragmentação dos conteúdos, a extrema rotinização e a rígida hierarquia entre os sujeitos da escola eram as características essenciais desse modelo. Nesse paradigma curricular, "tanto trabalhadores como estudantes verão negadas suas possibilidades de poder intervir nos processos produtivos e educacionais dos quais participam" (Santomé, 1998, p. 13).

Para Castells (2002), a característica principal do atual paradigma produtivo é o fato de que "a produção é gerada e a concorrência é feita em uma rede global de interação" (p. 87), que possui como base as tecnologias da informação. Uma das propriedades essenciais do novo paradigma é a inovação permanente, que irá demandar um outro tipo de trabalhador. Enquanto para a execução das tarefas (mecânicas, repetitivas, sem iniciativa, participação e ausência de comunicação) realizadas no taylorismo, a ênfase recaía nas habilidades manuais, no novo paradigma produtivo, conforme Kuenzer (1998), a concepção tradicional de qualificação se amplia, "passando-se a exigir o desenvolvimento da capacidade de educar-se permanentemente e das habilidades de trabalhar independentemente, de criar métodos para enfrentar situações não previstas, de contribuir originalmente para resolver problemas complexos" (p. 73), o que demandará do trabalhador uma participação mais ativa, ligada a suas capacidades intelectuais.

\section{Aspectos formais do currículo: o currículo prescrito}

Uma das condições para que os cursos de ampliação da escolaridade proporcionem o desenvolvimento de capacidades subjetivas dos trabalhadores é que tais cursos organizem-se de forma a superar a organização escolar taylorista-fordista. Assim, a flexibilidade será uma das características dessa organização. As empresas e instituições parceiras procuram estruturá-los de forma que estejam adequados às necessidades, físicas inclusive, de reprodução da força de trabalho. Descreveremos alguns aspectos que ilustram essa realidade.

A carga horária dos projetos investigados não ultrapassava 12 horas-aula semanais. Os dias de aula variavam entre três e quatro, nunca passando de duas horas e 45 minutos por dia. A carga horária total era reduzida, caso, por exemplo, do programa do SENAI, nível primeira a quarta séries, que possuía 1050 horas, sendo 75 horas à distância. A maior parte das turmas variava de 10 a 25 alunos. Existia, em geral, algum esforço para adequar o horário das aulas ao horário de trabalho e em muitos casos as aulas eram no próprio local de trabalho, ocorrendo um pouco antes ou após a jornada. Além disso, na grande maioria dos cursos havia transporte para os trabalhadores, às vezes especialmente para as aulas, o que facilitava os deslocamentos do trabalho à escola e para suas residências. Existia controle da freqüência, 
mas os trabalhadores não eram impedidos de entrar na aula se tivessem faltas em excesso. Do ponto de vista da classe trabalhadora, essas condições estão longe de serem ideais, já que os turnos de aulas constituem um acréscimo à já extensa jornada de trabalho. Porém, são bem melhores do que as oferecidas pela educação de jovens e adultos que ocorre à noite nas escolas públicas, nas quais, em geral, os horários e a freqüência são mais rigidamente controlados, as condições materiais são precárias, as aulas duram de três a quatro horas e as salas de aula possuem maior número de alunos.

A avaliação também utilizava técnicas mais flexíveis, como a classificação dos alunos independentemente da última série cursada na escola e pareceres descritivos no final da etapa de estudos. Os conteúdos prescritos do ensino, por sua vez, não fogem às tradicionais listas, os livros didáticos constituindo importante apoio às aulas. Porém, os professores possuem muita flexibilidade na escolha dos conteúdos, como veremos melhor no próximo tópico.

Os objetivos e os aspectos teórico-metodológicos que constam dos projetos pedagógicos são ilustrativos de como a empresa procura "equilibrar" a liberação da subjetividade do trabalhador e a necessidade de enquadrá-la nos mecanismos da produtividade. Por vezes, os objetivos parecem tão libertários que entram em contradição com as possibilidades reais de realização no trabalho. Nos projetos que envolvem SESI, SENAI e empresas, por exemplo, nível de primeira a quarta séries, afirma-se que o currículo "é essencialmente transformador, onde se busca alcançar uma consciência reflexiva para o desvendamento da realidade" (p. 44).

No geral, porém, os objetivos revelam que as motivações das práticas pedagógicas estão claramente associadas às necessidades de formação de um novo trabalhador. Em um projeto que envolve empresa do ramo extrativista e uma secretaria municipal de educação, por exemplo, apontam-se como objetivos, entre outros, "elevar o nível de compreensão e participação dos funcionários no ambiente de trabalho" e "conscientizar os funcionários sobre a responsabilidade que possuem no processo de desenvolvimento da organização".

Os projetos pedagógicos revelam também o controle que as empresas procuram exercer sobre a formação dos trabalhadores. No projeto de uma empresa de alimentos, único em que a escola era da própria empresa, é apontado que o currículo deve ser organizado em consonância com, entre outros, "a política educacional da mantenedora", ou seja, a empresa. Além disso, os direitos e os deveres dos trabalhadores escolares eram normatizados no livro de estatutos dessa empresa, da qual eram funcionários. O Conselho Administrativo e Pedagógico era integrado pelos diretores da empresa, além de representante do corpo docente, orientador educacional e supervisor educacional, o diretor industrial tendo o poder de convocar o Conselho Pedagógico e Administrativo da escola. ${ }^{2}$

No âmbito de outra prática pedagógica, essa reunindo empresas, SESI, SENAI e uma universidade, no curso realizado em uma empresa do ramo metalúrgico, todos os entrevistados colocaram que há um grande envolvimento da empresa no processo, que periodicamente é avaliado, resultando, inclusive, na substituição de professores que segundo empresa e alunos não estavam adequados, sendo as provas supervisionadas pelo SENAI.

Assim, podemos dizer que, se o currículo prescrito, por um lado, flexibiliza aspectos ligados à organização curricular (como os conteúdos, horários, avaliação e outros), ele revela já o deslocamento da prescrição curricular para os ideais da empresa.

2 Por uma questão de custos, a empresa desativou essa escola. Os alunos foram transferidos para um curso supletivo da Secretaria Municipal de Educação, uma prática também financiada em boa parte pelas empresas. 


\section{O currículo em ação: currículo como forma de liberação e apropriação das capacidades subjetivas dos trabalhadores}

Na produção teórica da área da educação as mudanças no tipo de conhecimento valorizado na força de trabalho são expressas na polêmica discussão da qualificação e das competências. Um grande número de estudiosos afirma que as habilidades atualmente exigidas dos trabalhadores são diferentes da idéia presente no conceito de qualificação. Para Dugué (2004), por exemplo, a qualificação representa rigidez em oposição à flexibilidade exigida na produção atual. Segundo a autora,

...a noção de qualificação desenvolve-se em um contexto industrial taylorista. A organização é predeterminada, imposta; o trabalhador deve se moldar ao posto que ocupa. Ter uma qualificação é dispor dos conhecimentos necessários para cumprir da melhor maneira o trabalho prescrito correspondente a um posto cujo conteúdo é fixado de maneira imutável (p. 25).

Já a competência está ligada ao trabalho nos moldes flexíveis, que necessita de trabalhadores autônomos, capazes de adaptação e aptos à criação "das condições necessárias para uma máxima eficácia". Nas formas de trabalho "neotayloristas", com os "processos participativos, os contratos por objetivos, as formas de auto-avaliação, o enfraquecimento das funções de controle ou de autoridade em proveito das funções de facilitação", é o trabalhador quem prescreve seu próprio trabalho (Dugué, 2004, p. 25).

As qualificações seriam formadas na escola, enquanto as competências teriam sua validade atestada pelo uso efetivo nas condições de realização do trabalho (Kuenzer, 2003; Tanguy, 1997). Além disso, reúnem um grande número de habilidades e possuem um caráter muito mais subjetivo, envolvendo inclusive o conhecimento tácito, que, conforme Nonaka e Takeuchi (1997), "é o conhecimento pessoal incorporado à experiência individual e envolve fatores intangíveis como, por exemplo, crenças pessoais, perspectivas e sistemas de valor" (p. 13).

Um aspecto essencial das competências, ao qual nem sempre a literatura dá a devida atenção, é que elas são, ao menos em grande parte, forjadas pelos próprios trabalhadores. Como afirma Roche (2004), "mesmo as tarefas mais rotineiras dão lugar a estratégias cognitivas: as competências seriam uma construção social dos próprios atores e não uma imposição da organização" (p. 44).

De fato, segundo Rosa (1998), as novas formas de trabalho revelam as capacidades de intervenção dos trabalhadores, as microescolhas e a solidariedade política e moral entre eles, assim como as regras que criam, a partir das já existentes, as prescritivas de suas atividades. $\mathrm{O}$ trabalhador passa a ser entendido como aquele que "pensa e age" em oposição ao trabalhador "executante" do taylorismo, cumpridor das regras e métodos de trabalho.

No entanto, ao mesmo tempo em que se revelam as capacidades dos trabalhadores, elas são apropriadas pelo capital. E especialmente nas formas de trabalho atuais, entendemos que o objetivo é "capturar o que é da ordem da subjetividade do homem como trabalhador, ou seja, estas capacidades e criação - sinergias, tanto individuais quanto coletivas" que produzem e reproduzem "uma outra eficiência produtiva em relação à prescrita pela direção da empresa” (Rosa, 1998, p. 7).

Essas implicações das competências têm estado bastante ausentes das discussões sobre as novas diretrizes curriculares da educação básica, as quais aquelas têm invadido cada vez mais. Nossas pesquisas revelam que o currículo das práticas de ampliação da escolaridade desenvolvidas pelas empresas possibilita a expressão das capacidades subjetivas dos trabalhadores, logo, sua apropriação pelo processo produtivo, uma conseqüência do que 
Stroobants (1999) chama de "visibilidade das competências". As informações revelam, no entanto, que não é necessariamente o trabalho com conteúdos cognitivos mais complexos o que gera a expressão dessas capacidades. $\mathrm{O}$ fato é que o espaço da sala de aula, desde que o trabalhador docente não proíba os trabalhadores de conversarem entre si, possibilitará que estes últimos construam formas menos rígidas de relacionamento social. Se os trabalhadores têm a possibilidade de organizarem-se por eles mesmos, são plenamente capazes de construir as condições dessa organização.

Claro que, se o professor utilizar técnicas como trabalhos em grupo ou formas de interdisciplinaridade, isso contribuirá para uma maior qualificação da prática pedagógica e, conseqüentemente, melhor aproveitamento pelo processo de produção. $O$ supervisor de produção da empresa extrativista expressa esse fato ao afirmar que "o próprio curso faz com que eles trabalhem bastante em grupo, e a gente hoje precisa disso também".

O currículo em ação da maioria das práticas investigadas é em grande parte construído espontaneamente por professores e alunos, tendo como mediação as relações sociais de produção das empresas, cujo espaço é muitas vezes contíguo à sala de aula. Podemos observar esse processo no apoio teórico-metodológico que utilizam os professores. Alguns dizem basear-se no construtivismo e realmente parecem utilizar metodologias que têm algo dessa teoria. A maior parte deles, porém, diz não seguir uma teoria específica. É comum, ao descreverem como preparam suas aulas, afirmarem que usam um pouco de cada coisa. $\mathrm{Na}$ prática, caem em um ecletismo muito grande ao misturar construtivismo, espontaneísmo e pedagogia tradicional. Seguem sobretudo um empirismo bastante adequado às intenções da empresa.

Uma professora da empresa extrativista, por exemplo, explicando sua metodologia, diz que usa um pouco de cada coisa, mas que sempre procura ler Paulo Freire. Para ela, "construtivismo" é "construir junto, e aqui a gente constrói muito junto com eles". Exemplifica dizendo que no início discutiu os conteúdos com os alunos e que, em função dessa discussão, tirou e colocou coisas diferentes do previsto inicialmente. Também diz que utiliza muitas coisas do cotidiano dos alunos e que não gosta de se apegar a livros. O empirismo fica ainda mais expresso na fala de outra professora da mesma empresa, que diz que se guia "pela intuição e pela aceitação" dos alunos. Ela também não segue "rigidamente" nenhuma teoria: "não vou muito atrás do papel, eu vou mais [atrás] do que eles precisam, exigem".

Nas observações das aulas nessa empresa, elas mostraram-se tradicionais no que diz respeito aos livros didáticos utilizados - os mesmos do ensino fundamental - e nos tipos de atividades. Mas há um clima de descontração, diálogo entre alunos e professora, além de atendimento individual. Os alunos ajudam-se entre si e lêem materiais alternativos trazidos pela professora quando terminam suas atividades.

O relacionamento entre professores e alunos foi um ponto bastante ressaltado por todos os entrevistados. Isso proporciona um envolvimento muito grande dos trabalhadores com a escola e a empresa, como mostra o depoimento de uma trabalhadora que disse se sentir compreendida pelos professores: "a gente sempre podia expressar a opinião da gente... aqui a gente ia trabalhar dentro da fábrica mesmo, convivência com os próprios alunos [colegas de trabalho], convívio depois na própria escola, constituía uma família mesmo".

A mudança nas formas de relacionamento entre os trabalhadores aparece na descrição que fazem as professoras quanto à forma como eles vão mudando suas atitudes no decorrer das aulas. A mesma professora citada acima afirma que eles eram "quietos" no início, mas que depois mudaram: "a gente fez um trabalho... debates, né, tinha que ver, cada um botando sua idéia, quem diria, aquele aluno... que tinha medo de dizer alguma coisa, agora ele fala bem... Eu percebo que eles vêm com muito medo... depois que passa aquela barreira... que eles vêm que eles podem fazer... aí eles vão embora". A perda desse "medo" que possuem os trabalhadores é apontada pelo diretor de uma empresa metalúrgica como uma exigência para que a empresa 
torne-se mais competitiva. Trata-se, dessa forma, de uma ruptura com um modo de se relacionar mais característico do taylorismo-fordismo, no sentido de que o trabalhador sintase mais à vontade para expor sua subjetividade.

Nas observações que fizemos nessa prática educativa, com professoras diferentes, os trabalhadores sentiam-se muito à vontade na aula. Na de língua portuguesa, para realizar uma atividade, organizaram-se como queriam, em grupos, duplas ou individualmente, trocando idéias entre si ou com a professora. Eles estavam despertos, apesar de expressarem fisicamente o cansaço do trabalho.

A mudança para formas de relacionamento mais espontâneas, que possibilitam maior troca e sistematização de conhecimentos pelos trabalhadores, fica evidenciada também no modo como trabalhadores escolares e das empresas expressam as diferenças entre os métodos "antigos" das escolas e os atuais. Uma professora de português e inglês (de uma prática educativa que envolvia empresas, secretaria de educação e universidade), por exemplo, afirma que os alunos comentavam que, quando estudavam na escola regular, não podiam olhar para o lado, que antes, o que o professor dizia era o certo, e que agora eles têm liberdade de dizer as coisas.

O resultado é uma maior capacidade de uso das habilidades subjetivas pelos trabalhadores na produção, aquilo que Nonaka e Takeuchi (1997) chamam de conversão do conhecimento tácito em explícito. O supervisor de produção de uma empresa metalúrgica, por exemplo, destaca que "precisava criar uma sistemática no setor com um funcionário que está estudando. Entreguei para ele o documento, expliquei como é que eu queria que ele fizesse e, no final do horário, ele apresentou um trabalho que eu fiquei até impressionado com a maneira como ele desenvolveu". Outros supervisores destacam a melhor "capacidade de expressão" dos trabalhadores. Dizem que as conversas entre eles "fluem mais" e que pensam mais antes de realizar o trabalho. Na mesma direção, outra funcionária de recursos humanos de uma empresa afirma que o conhecimento, antes, "ficava muito na cabeça de cada um" e que hoje a empresa pode contar com esse conhecimento.

\section{O currículo em ação: deslocamento do currículo prescrito para o âmbito do compromisso com a empresa}

As empresas expressam claramente que o objetivo principal da ampliação da escolaridade é poder contar com trabalhadores mais participativos e integrados aos ideais da empresa. Como afirma o diretor da extrativista, para aumentar a competitividade da empresa foi necessário investir em formação, pois "se a pessoa não entende o que faz, de que maneira ela pode fazer melhor com menor custo?". Assim, a formação está ligada à necessidade de "entender" melhor a produção, implicando esse entendimento em um maior compromisso dos trabalhadores: "as pessoas com educação, com clareza das coisas do mundo em que vivem, do meio em que atuam, elas conseguem perceber melhor o papel delas numa organização como a empresa. Se a pessoa tem instrução entende... qual é minha missão aqui?".

Pensamos que o depoimento desse gestor expressa exemplarmente um dos aspectos mais importantes da ampliação da escolarização do ponto de vista das empresas, qual seja, a assunção, pela força de trabalho, da missão da empresa. Nonaka e Takeuchi (1997) utilizam como metáfora para demonstrar essa questão o jogo de rúgbi. Explicam eles que, no rúgbi, "a bola passa de um jogador para o outro à medida que o time avança no campo, como uma unidade" (p. 10). Nas empresas japonesas, 
a bola que é passada de um jogador para o outro encerra a compreensão compartilhada da razão de ser da empresa, o rumo que está tomando, em que tipo de mundo quer viver e como tornar esse mundo realidade. Insights, intuições e pressentimentos altamente subjetivos também são levados em consideração. É isso o que a bola contém - ou seja, idéias, valores e emoções (p. 11).

Assim, se por um lado o currículo das práticas de ampliação da escolaridade dos trabalhadores das empresas serve para a expressão de suas capacidades subjetivas, essas capacidades não podem ser utilizadas como eles bem entenderem. Elas devem estar em função do capital e do aumento da produtividade. Desse modo, o currículo dessas práticas de educação de jovens e adultos contribui decisivamente para o deslocamento da prescrição, das tarefas de execução, para o compromisso com a missão empresa. Um compromisso, portanto, mais intelectual e mesmo emocional. Logo, mais subjetivo.

Como afirma Dugué (2004), o modelo das competências está associado à evolução dos modos de prescrição e à mobilização psíquica dos trabalhadores. As novas formas de trabalho, ao modificar o sistema hierárquico da empresa, levam "cada trabalhador a se considerar como parte constitutiva de uma enorme corrente que o liga, continuamente, à direção" (p. 25). Já Dadoy (2004) ressalta que os saberes relacionais e de cooperação impostos pelas novas condições de produção estão ligados à imposição, por essas últimas, de "um alto nível de responsabilização dos sujeitos, uma interiorização dos objetivos da empresa, uma exigência de qualidade do trabalho e de honestidade nas relações com a hierarquia e com os colegas" (p. 129).

O currículo em ação das práticas de ampliação da escolaridade desenvolvidas pelas empresas começa a realizar essa função modificando o ambiente nas salas de aula, como parte das mudanças nas relações de trabalho na empresa. Segundo Castells (2002), a necessidade de interatividade dos sistemas de inovação tecnológica implica sua dependência de "ambientes" propícios para trocas de idéias, problemas e soluções, o que Arnold (2001) chama de "entorno" necessário para que a aprendizagem e a difusão do conhecimento se realize. Por outro lado, esse ambiente criado permite a liberação da subjetividade do trabalhador e, ao mesmo tempo, a submissão dessa subjetividade aos objetivos da produtividade das novas formas organizacionais. Tendo por base a metáfora utilizada por Nonaka e Takeuchi que apresentamos acima, podemos dizer que, em que pese os trabalhadores tenham flexibilidade na condução da bola, eles não podem dar a ela o conteúdo que bem entendem.

Como descrevemos acima, o ambiente em muitas das salas de aula das empresas e das escolas públicas parceiras nas quais realizamos a pesquisa apresenta traços diferentes da escola taylorista, na qual os trabalhadores realizaram seus poucos anos de estudos. E essa possibilidade de se auto-organizarem em grupos, de participarem com opiniões, idéias, de conversarem entre si, encontra correspondência no ambiente maior das relações de trabalho da empresa, muitas vezes, como dissemos, contíguo às salas de aula. Por trás de ambos está a intenção da formação do novo ideal de trabalhador.

A criação de um compromisso com a empresa é manifestada já no sentimento de reconhecimento e agradecimento, pelos trabalhadores, das oportunidades de ampliação de seus estudos: "a gente tem tudo, tem a Kombi que busca nós, tem café, tudo grátis, lanche, material. A gente só entrou com a nossa vontade". Eles sabem que os estudos trazem a possibilidade de valorização ou manutenção do valor de sua força de trabalho. Como afirma um trabalhador, "se tu não tem o estudo, já fica mais reprimido, tu fica... vou ter que me cuidar... o cara capricha, né, só que não tem aquele medo... que precisa daquele emprego". Muitos dos trabalhadores entrevistados destacam a importância da busca de novos conhecimentos, as melhorias nas condições de vida proporcionadas pelo aumento de seus conhecimentos formais, assim como a possibilidade de ajudar os filhos na escola. 
Mas o mais importante, para a empresa, é que a volta ao estudo proporcionou uma melhora no relacionamento entre os trabalhadores. Um trabalhador da empresa extrativista, por exemplo, diz que no início só falavam do "colégio": "como tu foi em tal matéria, o que tu estás aprendendo, o que está sendo difícil prá ti... A gente trabalha no mesmo turno, mas cada um no seu setor, aí tu vem para cá [para a aula], tu fica quase três horas junto, então o relacionamento melhorou, a gente tem mais entrosamento".

A contigüidade física à produção dos ambientes de algumas das práticas investigadas é um importante elemento para a criação de um compromisso com a empresa. Freqüentemente as aulas ocorrem no mesmo lugar onde são dados os demais cursos ou treinamentos. Os materiais, livros, cartazes, murais são os da empresa e auxiliam no enquadramento dos trabalhadores nesse ambiente. Em algumas empresas, como na de móveis, os trabalhadores vão à aula com o uniforme, ajudando a confundir o ambiente e o horário de trabalho com o de estudo. Em pesquisa sobre formação de trabalhadores em nível de supletivo, que ocorre dentro de uma empresa do Vale dos Sinos, Rio Grande do Sul, Oliveira (2001) constatou que essa mescla dos ambientes de estudo e trabalho levava a que os trabalhadores "carregassem" os elementos de um ambiente para outro:

o que acontecia na fábrica, as relações que se travavam com as chefias nos diferentes setores, entravam para dentro da sala de aula e se misturavam aos encantamentos de um texto lido ou construído com os colegas, ou à releitura de uma obra-de-arte (p. 2).

Esse processo é facilitado pela implementação, juntamente com os cursos de ampliação da escolaridade dos funcionários, de técnicas de relações humanas que incentivam um maior relacionamento afetivo e emocional entre os trabalhadores. Como revela o boletim interno de uma empresa de confecções, que afirma que é preciso vencer o tabu de que a empresa não é um lugar de relações pessoais e de afeto, e que isso faz parte de uma cultura que contraria o lado humano do trabalho: "a identificação do colaborador com a empresa só é possível quando ele gosta do que faz e, sobretudo, das pessoas com as quais trabalha diariamente". Tanto nessa empresa, como na extrativista, o ambiente - que parece de harmonia, com "todo mundo feliz", como diz o gestor desta última - contrasta com o caráter prescritivo que se percebe no conteúdo ideológico dessas mensagens.

\section{Conclusão}

Embora na área da educação sempre lembremos da afirmação de Gramsci de que "todos os homens são intelectuais", acreditamos que ainda temos muito a caminhar no reconhecimento das formas como os trabalhadores expressam sua intelectualidade nas relações sociais de produção, em parte pelo seu caráter de "invisibilidade". As empresas, no entanto, deram-se conta das imensas capacidades produtivas reprimidas pelo autoritarismo taylorista e passaram a desenvolver formas de apropriar-se desses saberes.

Os aspectos informais do currículo das práticas pedagógicas investigadas expressam a intenção declarada da formação de um trabalhador flexível. Os conteúdos formais da escola tradicional têm pouca importância nesse processo. O conteúdo mais importante da formação realizada nas práticas pedagógicas investigadas só pode ser percebido mesmo no currículo em ação, acontecendo na sala de aula e sob influência direta das relações de produção da empresa. Só aí é possível identificar o currículo atuando para formar o trabalhador flexível.

Nesse processo, como dissemos, os trabalhadores são pelo menos um dos principais artífices, pois são eles mesmos que, através da quebra da rigidez instalada em suas relações sociais, estabelecem entre si maiores possibilidades de interação e daí desenvolvendo melhor 
capacidades como comunicação e iniciativa, que por sua vez permitem que um sem número de "conteúdos" do processo de produção seja também aprendido e dividido entre eles. Coletivamente passam a ser capazes de criar coisas que antes não eram permitidas.

No entanto, como afirmamos, a prescrição não deixou de existir nesse novo currículo. Embora, em boa medida, o desenvolvimento de uma melhor capacidade de comunicação se dê de forma espontânea pelos trabalhadores, esse não é apenas um conteúdo que, entre tantos, eles desejam desenvolver melhor porque lhes possibilitará um melhor relacionamento entre si. Trata-se de uma exigência das novas formas de organização do trabalho e, desse modo, uma exigência também do currículo das práticas pedagógicas desenvolvidas pelas empresas. Ela possui um componente prescritivo, que diz respeito à utilização da "nova" capacidade a serviço da missão da empresa.

Esse caráter contraditório está presente também nas metodologias participativas utilizadas na escola regular. Nesse sentido, devemos nos perguntar quando tais metodologias participativas possuem como objetivo de fato levar à formação de alunos capazes de inserirem-se ativamente na luta por melhores condições de vida para si e quando tais metodologias visam apenas formar saberes que serão apropriados para a maior produtividade do capital.

\section{Referências}

Arnold, R. (2001). Nuevos métodos en el trabajo de formación en las empresas. Revista Eletrônica de Administração, 6 (1).

Castells, M. (2002). A sociedade em rede. (6 $6^{\mathrm{a}}$ ed. atualizada). São Paulo: Paz e Terra.

Dadoy, M. (2004). As noções de competência e competências à luz das transformações na gestão da mão-de-obra. In A. Tomasi (Org.), Da qualificação à competência: pensando o século XXI (pp. 105-142). Campinas: Papirus.

Dugué, E. (2004). A lógica da competência: o retorno ao passado. In A. Tomasi (Org.), Da qualificação à competência: pensando o século XXI (pp. 19-32). Campinas: Papirus.

Gitahy, L. (2001). Redes e flexibilidade: da mudança das práticas quotidianas a uma nova trama produtiva. Seminário Temático Interdisciplinar Os Estudos do Trabalho: novas problemáticas, novas metodologias e novas áreas de pesquisa 1999-2000. São Paulo. [Digitado]

Kuenzer, A. Z. (2003). Competência como práxis: os dilemas da relação entre teoria e prática na educação dos trabalhadores. Boletim Técnico do SENAC, Rio de Janeiro, 29 (1).

Kuenzer, A. Z. (1998). Desafios teórico-metodológicos da relação trabalho-educação e o papel social da escola. In G. Frigotto (Org.), Educação e crise do trabalho: perspectivas de final de século (pp. 5-75). Petrópolis: Vozes.

Nonaka, I. \& Takeuchi, H. (1997). Criação de conhecimento na empresa: como as empresas japonesas geram a dinâmica da inovação (6 ${ }^{\underline{a}}$ ed.). Rio de Janeiro: Campus.

Oliveira, D. M. de (2000). Máquinas e silêncios: construindo significados no e para além do supletivo de trabalhadores. 23ํㅡㄹ Reunião Anual da Anped.

Roche, J. (2004). A dialética qualificação-competência: estado da questão. In A. Tomasi (Org.), Da qualificação à competência: pensando o século XXI (pp. 33-50). Campinas: Papirus.

Rosa, M. I. (1998). Do governo dos homens: "novas responsabilidades" do trabalhador e acesso aos conhecimentos. Educação $\mathcal{E}$ Sociedade, 19 (64), 130-147.

Sacristán, J. G. \& Gómez, A. I. P. (2000). Compreender e transformar o ensino (4aㅡ ed.) Porto Alegre: Artmed. 
Santomé, J. T. (1998). Globalização e interdisciplinaridade: currículo integrado. Porto Alegre: Artes Médicas.

Schwartz, Y. (2002). A abordagem do trabalho reconfigura nossa relação com os saberes acadêmicos: as antecipações do trabalho. In M. C. P. Souza-e-Silva \& D. Faïta (Orgs.), Linguagem e trabalho: construção de objetos de análise no Brasil e na França (pp. 109-137). São Paulo: Cortez.

Stroobants, M. (1999). Trabajo y competencias: recapitulación crítica de los enfoques sobre los saberes en el trabajo. Calificaciones y Empleo, 21 (1), 1-11.

Silva, T. T. da (1999). Documentos de identidade: uma introdução às teorias do currículo. Belo Horizonte: Autêntica.

Zarifian, P. (1998). El modelo de competencia y los sistemas productivos. Oficina Internacional del Trabajo. Montevidéu: Cinterfor.

Wood, E. M. (2000). Democracia contra capitalismo: a renovação do materialismo histórico. São Paulo: Boitempo.

\section{Endereço para correspondência:}

mviegas@terra.com.br

Recebido em: 03/12/2007

Revisado em: 18/03/2008

Aprovado em: 02/04/2008 